Review

\title{
Progress in the use of mesenchymal stromal cells for osteoarthritis treatment
}

\author{
Xiaotian Zhang, MD, $\mathrm{PhD}^{1}$, Jiyin He, MD, $\mathrm{PhD}^{1, * \dagger}$, Wen Wang, $\mathrm{MD}$, $\mathrm{PhD}^{2, * *}$ \\ ${ }^{1}$ Department of Orthopedics, Renji Hospital, Shanghai Jiao Tong University School of Medicine, Shanghai, China \\ ${ }^{2}$ Clinical Development, IASO Biotherapeutics Co., Ltd., Shanghai, China
}

\section{A R T I C L E I N F O}

\section{Article History:}

Received 23 July 2020

Accepted 29 January 2021

Key Words:

cell therapy

cell transplantation

mesenchymal stromal cells

osteoarthritis

\begin{abstract}
A B S T R A C T
Literature review of MSCs in the treatment of osteoarthritis in the past five years: Osteoarthritis (OA) is one of the most common chronic joint diseases, with prominent symptoms caused by many factors. However, current medical interventions for OA have resulted in poor clinical outcomes, demonstrating that there are huge unmet medical needs in this area. Cell therapy has opened new avenues of OA treatment. Different sources of mesenchymal stromal cells (MSCs) may have different phenotypes and cellular functions. Pre-clinical and clinical studies have demonstrated the feasibility, safety and efficacy of MSC therapy. Mitogen-activated protein kinase, Wnt and Notch signaling pathways are involved in the chondrogenesis of MSC-mediated treatments. MSCs may also exert effective immunoregulatory and paracrine effects to stimulate tissue repair. Therapy with extracellular vesicles containing cytokines, which are secreted by MSCs, might be a potential treatment for OA.

(c) 2021 International Society for Cell \& Gene Therapy. Published by Elsevier Inc. This is an open access article under the CC BY license (http://creativecommons.org/licenses/by/4.0/)
\end{abstract}

\section{Introduction}

Osteoarthritis $(\mathrm{OA})$ is one of the most common chronic joint diseases, with prominent symptoms caused by many factors. However, current medical interventions for OA have resulted in poor clinical outcomes, demonstrating that there are huge unmet medical needs in this area. Cell therapy has opened new avenues of OA treatment. Different sources of mesenchymal stromal cells (MSCs) may have different phenotypes and cellular functions. Pre-clinical and clinical studies have demonstrated the feasibility, safety and efficacy of MSC therapy. Mitogen-activated protein kinase (MAPK), Wnt and Notch signaling pathways are involved in the chondrogenesis of MSC-mediated treatments. MSCs may also exert effective immunoregulatory and paracrine effects to stimulate tissue repair. Therapy with extracellular vesicles (EVs) containing cytokines, which are secreted by MSCs, might be a potential treatment for OA.

\section{OA. and Cell Therapy}

\section{$O A$ and epidemiology}

In the 16th century, with the rapid development of anatomy, knowledge about joints and surrounding basic structures-including articular cartilage, ligaments that stabilize joints and synovial fluid within joints-solidified, and the clinical disease causing joint pain and stiffness was named OA, literally referring to inflammation of bones and joints [1,2]. OA is caused by many factors, such as degenerative damage to articular cartilage and reactive hyperplasia of joint edges and subchondral bone, which causes slowly developing joint pain, tenderness, stiffness, swelling and deformities, along with limited mobility. $\mathrm{OA}$ is the most common type of chronic joint disease and affects all structures of the joint $[3,4]$. Statistics indicate that there were 303 million patients with OA worldwide in 2017 [5]. The prevalence of symptomatic knee OA (Kellgren and Lawrence score $\geq 2$ and knee pain) in China in 2018 was $8.1 \%$; the prevalence was higher in women than men, and there were obvious regional differences (data from the China health and pension follow-up survey database, China Health and Retirement Longitudinal Study).

\section{Clinical manifestations and pathogenesis}

$\mathrm{OA}$ is the most common chronic disabling disease affecting elderly individuals. Joint pain and loss of function are the main clinical features of OA. Joint pain and tenderness are the most common clinical manifestations of OA, occurring in $36.8-60.7 \%$ of patients. Pain can occur in any joint but is most common in the hips, knees and interphalangeal joints [6]. In addition, OA can present with clinical

\footnotetext{
* Correspondence: Jiyin He, MD, PhD, Department of Orthopedics, Renji Hospital, Shanghai Jiao Tong University School of Medicine, Shanghai 200127, China.

** Correspondence: Wen Wang, MD, PhD, Clinical Development, IASO Biotherapeutics Co., Ltd., Shanghai 201203, China.

$\dagger$ These authors contributed equally to this work.

E-mail addresses: xiaotian6grass@sina.com (X. Zhang), chasehe@hotmail.com (J. He), wen.wang@iasobio.com (W.Wang).
} 
symptoms such as limited joint movement, joint deformity, creaking sensations in the bone and muscle atrophy. Diagnosis depends on both clinical and imaging features. Three typical manifestations of OA on X-rays are asymmetrical joint space narrowing in affected joints, subchondral bone sclerosis and/or cystic degeneration and osteophyte formation at the joint edges. However, nearly half of patients with imaging features of $\mathrm{OA}$ are asymptomatic, and more than half of patients without imaging features of OA exhibit symptoms [3]. OA is often symptomatic and has been diagnosed in the late stages of the disease process, with poor treatment results.

$\mathrm{OA}$ is a process of not only joint cartilage erosion but also joint tissue remodeling due to various causes, including obesity, joint instability and trauma [7]. Some researchers describe the joint as an organ of common significance, and extensive pathological changes in $\mathrm{OA}$ are considered "joint failure". Joint tissue hyperplasia is one of the most significant early features of the disease and includes articular cartilage thickening, chondrocyte proliferation, increased matrix synthesis, subchondral bone densification with low mineralization and increased bone marrow fat content [8]. The relationship between $\mathrm{OA}$ and hypertension, hypercholesterolemia and blood glucose suggests that systemic and metabolic components are involved; thus, $\mathrm{OA}$ is also considered a systemic musculoskeletal disease (Figure 1) [9].

\section{OA treatment}

Although many treatment methods for OA have been developed, the clinical results of most are unsatisfactory because cartilage tissue cannot fundamentally be repaired [10]. Many guidelines list paracetamol as the treatment of choice, and other nonsteroidal anti-inflammatory drugs as well as corticosteroid injections and tramadol help relieve symptoms in many patients with OA [11]. Because OA is a chronic disease, long-term medication also confers a series of risks [12]. In addition to traditional anti-inflammatory drugs, researchers have developed new drugs, including trans-capsaicin injection (CNTX-4975) [13] and lutikizumab [14], a humanized IL- $1 \alpha / \beta$ dual variable domain immunoglobulin that simultaneously blocks IL- $1 \alpha$ and IL- $1 \beta$. In addition, investigators have tried to promote tissue repair methods such as MSC injection and platelet-rich plasma (PRP) $[15,16]$. For advanced hip or knee OA, joint replacement is an effective treatment option. However, an implant is an artificial joint with a certain life span and is not always a once-in-a-lifetime therapy. According to structural risk assessments, the life span of such implants is 25 years $[17,18]$.

\section{Cell therapy and its application in cartilage injury}

Cell therapy refers to the use of certain cells with specific functions that are obtained by biological engineering methods or through in vitro expansion, special culture systems and other treatments. These cells have enhanced immune responses, killed pathogens and tumor cells and promoted tissue and organ regeneration. The use of cell therapy in many refractory diseases is very promising, and it is also one of the most promising strategies for treating tumors. Some researchers have envisaged that by constructing $\mathrm{T}$ cells expressing chimeric antigen receptors-synthetic receptors that fuse tumor-specific extracellular antibody fragments with signal chains from primary T-cell receptors-they can target certain molecules to eradicate difficult to treat B-cell malignancies [19]. Since the introduction of induced pluripotent stem cell (iPSC) technology a decade ago, great progress has been made in stem cell biology and regenerative medicine. Researchers have treated Parkinson's disease with cell therapy through allografts of embryonic stem cells or iPSCs [20]. Type 1 diabetes, which usually affects children, is an autoimmune disease that can cause progressive destruction of pancreatic islet $\beta$ cells, eventually leading to loss of insulin secretion, which in turn leads to hyperglycemia. Stem cell therapy promotes a new treatment model by allowing the development of islet $\beta$ cells [21]. Cell therapy also shows considerable therapeutic prospects for spinal muscular atrophy [22], primary immunodeficiency, metabolic diseases and hemoglobin diseases [23], in addition to the aforementioned diseases.

MSCs have chondrogenic capacity and have recently been considered a potential tool for OA repair [24]. Intra-articular injection of MSCs can replace autologous chondrocyte implantation for repair of joint surface injuries [25]. The use of iPSC technology, which can generate cells that can self-renew and produce any somatic cell type for an extended time, may overcome these problems. Other iPSC cartilage generation strategies, including tissue engineering techniques to simulate the human cartilage development microenvironment, are also being improved. In this review, the authors summarize the characteristics of MSCs; the differences between various types of MSCs; the clinical research progress made on the use of MSCs for treating $\mathrm{OA}$; the underlying mechanisms of action, including the signaling pathways involved in treating $\mathrm{OA}$; and the latest results of in vitro and in vivo experiments.

\section{MSCs for OA Treatment}

\section{Pre-clinical experimental model of MSCs for OA treatment}

In 2003, Murphy et al. [26] used a single direct intra-articular injection of autologous bone marrow-derived MSCs (BM-MSCs) suspended in a sodium hyaluronate solution to treat goats in a model of unilateral knee OA. Twenty weeks after the injection, the medial meniscus had regenerated significantly in the injected joints, and the implanted cells were detected in the newly formed tissue. In addition, compared with the joints treated with cell-free carriers alone,
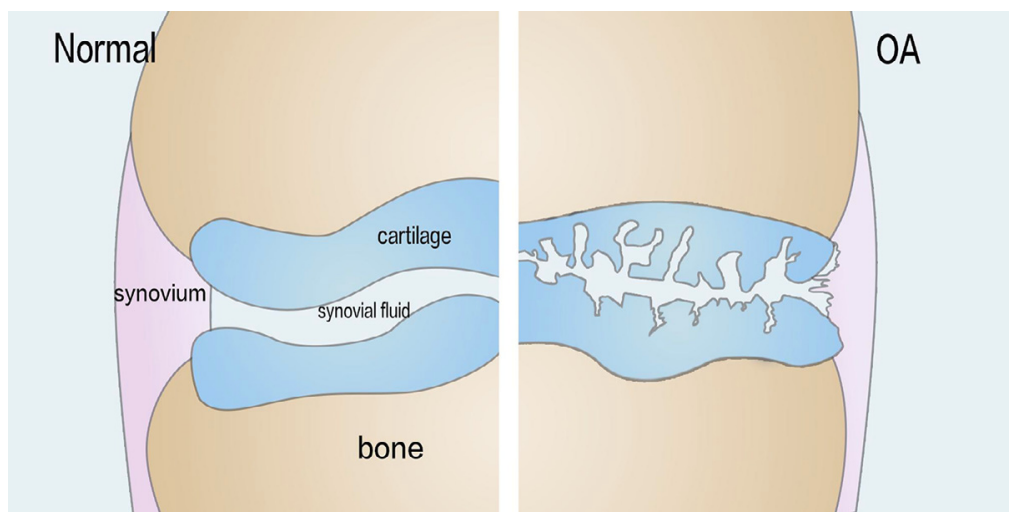

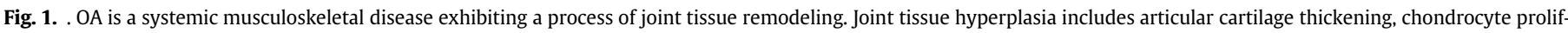
eration, increased matrix synthesis, subchondral bone densification with low mineralization and increased bone marrow fat content. 
the injected joints exhibited decreased articular cartilage degeneration, osteophyte formation and subchondral sclerosis. Since then, in multiple animal models of cartilage defects and anterior cruciate ligament transection (ACLT), the MSC treatment group has shown improvements in cartilage healing both histologically and morphologically (Table 1 ).

The types of injected cells have also been diversified from the initial BM-MSCs to adipose-derived MSCs (AD-MSCs), umbilical cordderived MSCs (UC-MSCs), human amniotic membrane-derived MSCs (hAMSCs)/human chorionic membrane-derived MSCs, etc. In a dog model of knee arthritis established in 2018, researchers injected allogeneic UC-MSCs $\left(1 \times 10^{6}\right.$ cells $)$, and on day 3 , day 7 , day 14 and day 28 after treatment, they observed the structure of the dogs' knee joints by magnetic resonance imaging (MRI), ultrasound and X-ray imaging [35]. The high signal in the MRI T2-weighted images of dogs in the treatment group decreased, the echo-free space in the B-mode images basically disappeared and the continuous linear low-echo area of the pulley groove thickened. X-rays showed that the jagged defect in the sacrum of dogs in the treatment group had improved, and the low-density gap between the sacrum and the ventral side of the sacrum gradually increased. After 35 days of treatment, the neocartilage in dogs in the treatment group exhibited visible new tissue, with fibers arranged more irregularly than those in the existing tissues. In addition, more vacuoles were observed in the cartilage of dogs in the untreated control group, but no collagen fibers were seen in this cartilage, and the thickness of the neocartilage was greater in dogs in the treatment group.

Other investigators transplanted hAMSCs into the non-cartilage tissue of mice or implanted them into collagen defects in rat bones to detect type II collagen and cartilage proteoglycans, demonstrating that hAMSCs can differentiate into cartilage both in vitro and in vivo [47]. In addition to the aforementioned cells, human meniscus stem/ progenitor cells (hMeSPCs) have been found to exhibit the characteristics of MSCs and high expression levels of collagen II. Intra-articular injection of hMeSPCs induced meniscus defects in rats 4 weeks after meniscectomy and induced significantly more new tissue formation and extracellular matrix (ECM) deposition than the control treatment [48]. Twelve weeks after meniscectomy, compared with the control treatment, intra-articular injection of hMeSPCs reduced surface irregularities and the expression of OA-labeled collagen I and X but maintained high collagen II expression.

However, in many animal studies of intra-articular injection of MSCs, heterogeneous contaminants (such as fetal calf serum) have caused significant adverse clinical reactions, and such contaminants should be removed. More importantly, in one study involving repeated intra-articular injections of allogeneic MSCs, adverse clinical reactions were seen with a second injection administered 4 weeks after the first, most likely because of adaptive immune activation of allogeneic MSCs [37]. Therefore, researchers studied the rat OA model and found that the treatment of cartilage defects in rats with exosomes injected with heterologous MSCs was associated with complete recovery of cartilage and subchondral bone, which was characterized by the presence of hyaline cartilage with good surface regularity and complete integration with the adjacent cartilage [49]. ECM deposition was very similar to that observed in the age-matched nonsurgical control group. By contrast, only fibrous repair tissue was found in the group with contralateral phosphate-buffered salinetreated defects. This study demonstrated for the first time the efficacy of human embryonic MSC exosomes in cartilage repair.

With the continuous development of tissue engineering and three-dimensional printing technology, it seems that a new solution has been found for large cartilage defects, which were difficult to repair in the past. The combination of MSCs and biomaterials not only promotes the recovery of the cartilage layer but also promotes the regeneration of subchondral bone. In 2017, Chinese researchers seeded autologous BM-MSCs into polyglycolic acid (PGA)/polylactic acid (PLA) scaffolds, which were used to repair articular cartilage defects after 2-12 weeks of cartilage induction. The results showed that in terms of cartilage quality and function, the repaired cartilage in the 4th and 8th week groups reached a level similar to that of natural articular cartilage [46]. Zhang et al. [47] seeded MSCs into threedimensional printed poly- $\varepsilon$-caprolactone scaffolds and found that MSCs could increase the regeneration and mechanical strength of fibrocartilage tissue, providing a functional method of protecting articular cartilage from osteochondral damage after total meniscectomy.

\section{Clinical trials of MSCs for OA treatment}

The aforementioned successful pre-clinical experimental animal model studies led to the start of many clinical trials (Table 2). In numerous prospective randomized controlled clinical trials, the autologous BM-MSCs and AD-MSCs treatment groups achieved significant improvements in Tegner, Lysholm and International Knee Documentation Committee scores and visual analog scale pain scores [50,51]. Unlike BM-MSCs, autologous AD-MSCs are generally obtained from the abdominal fat, which is more convenient for surgery and less damaging to patients. Regarding the injected cell dose, Jo et al. [52] constructed three dose gradients of autologous ADMSCs: low $\left(1 \times 10^{7}\right.$ cells $)$, medium $\left(5 \times 10^{7}\right.$ cells $)$ and high $\left(1 \times 10^{8}\right.$ cells). The groups treated with high doses had significantly improved Western Ontario and McMaster Universities Osteoarthritis Index scores; clinically significant reductions in pain; regeneration of thick, transparent cartilage by histology; and no significant adverse reactions.

Intra-articular injection of human UC-MSCs (once monthly for 2 months) and intra-articular injection of sodium hyaluronate (once weekly for 5 weeks) have also been compared [58]. The two groups exhibited no significant differences in knee joint function scores and SF-36 scale scores after 1 and 2 months of treatment. However, the scores of the cell therapy group were significantly better than those of the control group at 3 and 6 months after treatment. Similar results were observed in a clinical trial with a 7-year follow-up period [59]. Human UC-MSCs showed histological manifestations of hyaline cartilage formation at 1 year of treatment, and MRI at 3 years showed that the regenerating cartilage persisted over the previous 7 years without bone or tumor formation. In addition, intra-articular injection of allogeneic placenta-derived MSCs significantly improved knee OA pain, symptoms, activities of daily living, quality of life, sport and recreation factors and clinical indicators of knee range of motion. During the 24 weeks of follow-up in another study, no differences were observed in evidence of tissue damage, tumor formation, pulmonary embolism or liver or kidney damage [63]. Pain was reduced, but the effects on activities of daily living and symptom improvement began to decrease after 8 weeks of treatment. Therefore, the authors believe that multiple injections may improve and prolong the therapeutic effect of placenta-derived MSCs because OA is a continuous process of joint destruction. Compared with BM-MSCs and AD-MSCs, placenta-derived MSCs and UC-MSCs have two major advantages: (i) they have similar regenerative potential but low immunogenicity and (ii) they are easily available by non-invasive methods.

Regarding MSC scaffolds, the literature has reported the use of PRP and hyaluronic acid (HA). Platelets contain more than 1500 biologically active proteins [69]. These diverse compounds include growth factors, peptide hormones, chemokines, fibrin and proteins with antibacterial and fungicidal properties. However, PRP is limited by variability in its preparation and the amount of biologically active factors it contains. In addition, platelet counts can vary based on the donor's age, health status, hydration and sex. In addition, PRP contains factors-namely, vascular endothelial growth factor (VEGF)that may adversely affect joints and MSCs. The benefits of HA may go beyond its role as a scaffold. Pre-clinical studies have observed that 
MSC-based treatments in pre-clinical large animal models of OA.

\begin{tabular}{|c|c|c|c|c|}
\hline Species & Animal model & Cell source & Dose, cells & Scaffold \\
\hline Goat [26] & & & & $\begin{array}{l}\text { ACLT + meniscectomy for } \\
6 \text { weeks }\end{array}$ \\
\hline $2 \times 10^{6}$ & $\mathrm{HA}$ & $\begin{array}{l}\text { Articular carti- } \\
\text { lage degener- } \\
\text { ation, osteo- } \\
\text { phytic remod- } \\
\text { eling and } \\
\text { subchondral } \\
\text { sclerosis were } \\
\text { reduced in } \\
\text { cell-treated } \\
\text { joints. }\end{array}$ & & \\
\hline Pig [27] & $\begin{array}{l}\text { Partial-thickness } \\
\text { cartilage defect }\end{array}$ & $\begin{array}{l}\text { Autologous } \\
\text { BM-MSCs }\end{array}$ & $9 \times 10^{5}$ & $\mathrm{HA}$ \\
\hline Rabbit [28] & $\begin{array}{l}\text { Full-thickness } \\
\text { osteochondral } \\
\text { defect }\end{array}$ & $\begin{array}{l}\text { Allogeneic syno- } \\
\text { vial MSCs }\end{array}$ & $1 \times 10^{7}$ & - \\
\hline Rabbit [29] & $\begin{array}{l}\text { Osteochondral } \\
\text { defect }\end{array}$ & $\begin{array}{l}\text { Allogeneic } \\
\text { BM-MSCs }\end{array}$ & $1 \times 10^{7}$ & $\begin{array}{l}\text { OPF (oligo(poly(ethylene } \\
\text { glycol) fumarate))/ } \\
\text { GMP } \\
\text { + TGF- } \beta 1\end{array}$ \\
\hline Guinea pig [30] & Spontaneous OA & Human MSCs & $7 \times 10^{6}$ & $\mathrm{HA}$ \\
\hline Rabbit [31] & ACLT for 8 weeks & $\begin{array}{l}\text { Allogeneic } \\
\text { AD-MSCs }\end{array}$ & $2 \times 10^{6}$ & $\mathrm{HA}$ \\
\hline Rabbit [32] & MMR & $\begin{array}{c}\text { Xenogeneic } \\
\text { UC-MSCs }\end{array}$ & $3.5 \times 10^{6}$ & - \\
\hline $\operatorname{Dog}[33]$ & ACLT for 2 months & $\begin{array}{l}\text { Autologous AD- } \\
\text { MSCs }\end{array}$ & $1 \times 10^{7}$ & PRP \\
\hline Horse [34] & $\begin{array}{l}\text { Non-osteochondral } \\
\text { defect }\end{array}$ & $\begin{array}{c}\text { Autologous/ } \\
\text { allogeneic } \\
\text { BM-MSCs }\end{array}$ & $1 \times 10^{7}$ & - \\
\hline $\operatorname{Dog}[35]$ & $\begin{array}{l}\text { Patellar and femoral } \\
\text { condyle cartilage } \\
\text { defect }\end{array}$ & $\begin{array}{l}\text { Allogeneic UC- } \\
\text { MSCs }\end{array}$ & $1 \times 10^{6}$ & - \\
\hline Horse [36] & $\begin{array}{l}\text { OA of the metacar- } \\
\text { pophalangeal/ } \\
\text { metatarsophalan- } \\
\text { geal joints }\end{array}$ & $\begin{array}{l}\text { Allogeneic UC- } \\
\text { MSCs }\end{array}$ & $1 \times 10^{7}$ & - \\
\hline Rabbit [37] & $\begin{array}{l}\text { Bilateral section of } \\
\text { ACL }\end{array}$ & $\begin{array}{l}\text { Allogeneic BM- } \\
\text { MSCs }\end{array}$ & $1 \times 10^{6}$ & - \\
\hline Porcine [38] & $\begin{array}{l}\text { Full-thickness chon- } \\
\text { dral injury of } \\
\text { knees }\end{array}$ & $\begin{array}{l}\text { Human UC- } \\
\text { MSCs }\end{array}$ & $5 \times 10^{6}$ & $\mathrm{HA}$ \\
\hline Sheep [39] & $\begin{array}{l}\text { Unilateral medial } \\
\text { meniscectomy }\end{array}$ & $\begin{array}{l}\text { Autologous BM- } \\
\text { MSCs }\end{array}$ & - & HA \\
\hline Porcine [40] & ACL transection & $\begin{array}{l}\text { Human BM- } \\
\text { MSCs }\end{array}$ & - & $\begin{array}{l}\text { Collagen } \\
\text { scaffold }\end{array}$ \\
\hline $\operatorname{Dog}[41]$ & CR & $\begin{array}{l}\text { Autologous BM- } \\
\text { MSCs }\end{array}$ & $5 \times 10^{6}$ & - \\
\hline
\end{tabular}

Outcome

\section{Allogeneic}

At 12 weeks, the Wakitani scores showed marked improvement in the quality of repair tissue in the MSC-treated group.

The histological score of the treated group was consistently better at 4 weeks, 12 weeks and 24 weeks than that seen in the control group. Treatment with the MSCs suspension promoted cartilage regeneration.

Defects were filled with hyaline cartilage-like tissue with zonal organization and intense glycosaminoglycan staining.

At 5 weeks post-transplantation, partial cartilage repair was noted in the HA-MSC group, with type II collagen around both residual chondrocytes and transplanted MSCs in the OA cartilage.

Eight weeks after ACLT, loss of cartilage was observed in both the medial and lateral condyles, whereas the cartilage matrix was predominantly retained in AD-MSC-treated knees.

Early IA injection was effective in preventing OA signs in rabbit knees following MMR. UC-MSCs targeted the synovium and modulated the gene expression pattern of synoviocytes to promote an anti-catabolic environment.

The levels of ECM-related genes increased through upregulation, whereas protein expression levels of inflammatory cytokines were decreased through the inhibitory effects of PRP and MSCs on chondrocyte apoptosis and inflammatory cytokine production.

Repeated IA injection of allogeneic MSCs resulted in adverse clinical reactions after a second injection administered 4 weeks after the first. It is most likely because of adaptive immune activation of allogeneic MSCs

Canine UC-MSCs promoted the repair of cartilage and patellar injury in OA, improved healing of the surrounding tissues and reduced the inflammatory response.

At the end of the study, five horses returned to their intended level of use, eight returned to a lower level and nine remained lame. The mechanism of action of MSCs is currently thought to be an immunomodulatory one rather than any regenerative effects brought about by the MSCs' differentiation into chondrocytes

A single injection of MSCs was not enough to restore the condition of joints with OA. This is in contrast to multiple injections of MSCs, which had the ability to replace lost cells as well as reduce inflammation.

The treated knees showed significant gross and histological improvements in hyaline cartilage regeneration compared with the control knees. The International Cartilage Repair Society histological score was higher for the treated knees than the control knees.

BMC-HA (autologous Bone Marrow Concentrate) treatment showed greater inhibition of OA progression compared with MSC-HA, leading to a reduction in inflammation of cartilage, meniscus and synovium. Both MSC and BMC combined with HA reduced inflammation and contributed to switch-off fibrotic and hypertrophic processes.

At 5 months after implantation, significant differences in the quality of the regenerated tissue were found between the human BM-MSC-embedded scaffold group and the control group. Newly generated tissue was only observed at the site of implantation with the human BM-MSC-embedded scaffolds.

No adverse events after BM-MSCs treatment were detected. Circulating CD8+ T lymphocytes were lower after BM-MSCs

injection. Systemic and intra-articular injection of autologous BM-MSCs in dogs with partial CR suppressed systemic and stifle joint inflammation, including CRP concentrations. 


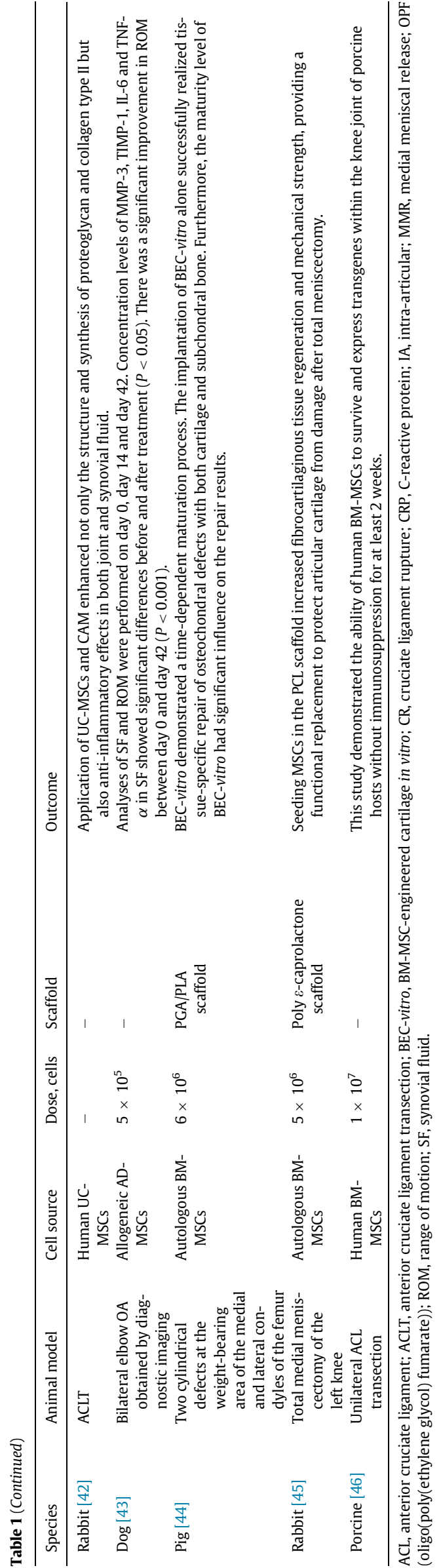

by combining HA with fibroblast growth factor (FGF) 2, both synovial cell migration and chondrocyte migration can be enhanced [70].

To date, most published clinical trials have reported that MSC therapy is a safe and promising treatment for OA. In addition, researchers in Mexico reported a new type of cell-free bioactive preparation called BIOF2(producted by Esteripharma Mexico (Mexico City, Mexico)), a patented formula composed of corticosteroids, insulin and organic acids [68]. Injection in the knee joint showed a therapeutic effect on $\mathrm{OA}$.

\section{Potential Mechanism of MSCs in OA Treatment}

$\mathrm{OA}$ is a disease involving all tissues in the joint, especially the structural integrity of the articular cartilage. Its pathophysiology derives from various tissues, including cartilage, bone, synovium and capsular fibrous tissue. This concept replaces previous views centered on cartilage lesions and encourages exploration of the interactions between the various tissues that comprise joints.

Changes in chondrogenic phenotype, ECM and subchondral bone lesions in $O A$

Articular chondrocytes are stationary, mature cells that maintain the homeostasis of adult articular cartilage by preserving cell survival and the delicate balance between anabolism and catabolism. In OA, articular chondrocytes respond to the accumulation of noxious biochemical and biomechanical damage by transforming into hypertrophic cells, accompanied by abnormal matrix production and increased aggrecanase and collagenase activity. These pathological changes form a vicious cycle that leads to irreversible damage to cartilage structure and function [71].

Overall dysregulation of the chondrocyte transcription network has been observed in OA. OA chondrocytes are activated by exposure to an abnormal biochemical/biomechanical environment. The signals leading to phenotypic transformation of $\mathrm{OA}$ chondrocytes include nuclear factor-kB (NF- $\kappa \mathrm{B})$ signals and the effects of the transcription factors SOX9, HIF-2 $\alpha$ and runt-related transcription factor 2 (RUNX2). Some studies have reported that SOX9, COL2A1 and ACAN messenger RNA levels decrease with increasing severity of OA [72] and that the increased expression of SOX9 in early disease is associated with decreased production of ADAMTSs (newly identified metalloproteinases) and increased expression of COL2A1, cartilage oligomeric protein and ACAN [73]. These abnormally expressed mediators have anti-anabolic and pro-catabolic functions in chondrocytes and can disrupt the SOX9-CBP/p300 interaction $[74,75]$. NF- $\kappa$ B signaling pathways also play a central role in cartilage degradation [76] and articular chondrocyte differentiation to hypertrophic cells [77]. IKK $\beta$ and IKK $\alpha$, kinases that control the canonical and non-canonical NF- $\kappa \mathrm{B}$ pathways, respectively, are also necessary for inducing chondrocyte hypertrophy in vitro. In summary, stress and pro-inflammatory signals activate canonical NF- $\kappa$ B pathways, and by disrupting key regulatory networks, OA drifts toward hypertrophic changes.

Recent research has identified changes in SIRT1, DOT1L and other histone modifications in OA articular chondrocytes [78,79]. DNA methylation is the main mechanism by which cells maintain a stable phenotype. This process converts 5-methylcytosine to 5-hydroxymethylcytosine $(5 \mathrm{hmC})$. Evidence indicates that $5 \mathrm{hmC}$ is not only an intermediate product of the demethylation process but also an independent epigenetic marker that facilitates gene transcription and a "ready-to-go" epigenetic state [80]. IL- $1 \beta$ can increase the level of $5 \mathrm{hmC}$ in OA chondrocytes through TET1 [81]. Many genes related to $\mathrm{OA}$, such as matrix metalloproteinase (MMP) 3 in OA cartilage, may be regulated by a gain in $5 \mathrm{hmC}$. Total methylation is increased and expression of transcription factors is decreased in OA chondrocytes compared with healthy chondrocytes [82]. 


\begin{tabular}{|c|c|c|c|c|c|}
\hline $\begin{array}{l}\text { Sample size } \\
\text { (indications) }\end{array}$ & Study design & Cell source & Dose, cells & Scaffold & Outcome \\
\hline $\begin{array}{l}\text { One (degenerative joint } \\
\text { disease) [53] }\end{array}$ & $\begin{array}{l}\text { Follow-up visit at } 24 \\
\text { weeks after IA } \\
\text { injection }\end{array}$ & Autologous BM-MSCs & $4.56 \times 10^{7}$ & HA & $\begin{array}{l}\text { The patient had statistically significant cartilage and meniscus growth, as assessed by MRI, as well } \\
\text { as increased ROM and decreased modified VAS pain score. }\end{array}$ \\
\hline $\begin{array}{l}50 \text { (mild to moderate } \\
\text { knee OA) [50] }\end{array}$ & $\begin{array}{l}\text { Injection with MSC con- } \\
\text { centrate along with } \\
\text { arthroscopic } \\
\text { debridement }\end{array}$ & Autologous BM-MSCs & - & - & Overall OA outcome score, especially QoL, was improved. \\
\hline $\begin{array}{l}\text { Four (moderate to } \\
\text { severe knee OA) [54] }\end{array}$ & $\begin{array}{l}\text { IA injection of cultured } \\
\text { MSCs }\end{array}$ & Autologous BM-MSCs & $8-9 \times 10^{6}$ & - & Walking time and pain improved for three patients and remained unchanged for one patient. \\
\hline 25 (knee OA) [51] & $\begin{array}{l}\text { IA injection of cultured } \\
\text { MSCs combined with } \\
\text { arthroscopic } \\
\text { debridement }\end{array}$ & Autologous AD-MSCs & $1.89 \times 10^{6}$ & PRP & $\begin{array}{l}\text { The mean Lysholm, Tegner activity scale and VAS scores of patients in the study group improved } \\
\text { significantly. }\end{array}$ \\
\hline $\begin{array}{l}12 \text { (unicompartmental } \\
\text { knee OA) [55] }\end{array}$ & $\begin{array}{l}\text { IA injection of MSCs } \\
\text { with HA } 3 \text { weeks after } \\
\text { HTO and } \\
\text { microfracture }\end{array}$ & Autologous BM-MSCs & $1.5 \times 10^{7}$ & HA & Treatment was effective in improving both short-term clinical and MOCART outcomes. \\
\hline $\begin{array}{l}12 \text { (chronic knee pain) } \\
{[56]}\end{array}$ & $\begin{array}{l}\text { Follow-up visit } 1 \text { year } \\
\text { after IA injection }\end{array}$ & Autologous BM-MSCs & $4 \times 10^{7}$ & - & $\begin{array}{l}\text { Patients exhibited rapid and progressive improvement (approaching } 65-78 \% \text { after } 1 \text { year) on algo- } \\
\text { functional indices. }\end{array}$ \\
\hline $18($ knee OA) [52] & $\begin{array}{l}\text { IA injection in three } \\
\text { dose-escalation } \\
\text { cohorts and a follow- } \\
\text { up visit at } 6 \text { months } \\
\text { after high-dose } \\
\text { injection }\end{array}$ & Autologous BM-MSCs & $1-10 \times 10^{7}$ & - & $\begin{array}{l}\text { High-dose IA injection improved knee joint function and pain without causing adverse events and } \\
\text { reduced cartilage defects via regeneration of hyaline-like articular cartilage. }\end{array}$ \\
\hline $\begin{array}{l}55 \text { (partial medial } \\
\text { meniscectomy) [25] }\end{array}$ & $\begin{array}{l}\text { Single injection of cul- } \\
\text { tured MSCs } 7-10 \text { days } \\
\text { after meniscectomy }\end{array}$ & Allogeneic BM-MSCs & $(5-15) \times 10^{7}$ & HA & Treated patients had significant reductions in pain and significant increases in meniscal volume. \\
\hline $\begin{array}{l}18 \text { (symptomatic severe } \\
\text { knee OA) [57] }\end{array}$ & $\begin{array}{l}6 \text { months of follow-up } \\
\text { after a single intraar- } \\
\text { ticular injection }\end{array}$ & Autologous AD-MSCs & $2-50 \times 10^{6}$ & - & $\begin{array}{l}\text { The procedure was found to be safe and resulted in clinical improvement, with a reduction in pain } \\
\text { levels and WOMAC scores in all three groups. }\end{array}$ \\
\hline $\begin{array}{l}36 \text { (moderate or severe } \\
\text { degenerative knee } \\
\text { OA) [58] }\end{array}$ & $\begin{array}{l}6 \text { months of follow-up } \\
\text { after injection }\end{array}$ & Allogeneic UC-MSCs & $2-3 \times 10^{7}$ & - & $\begin{array}{l}\text { In the cell treatment group, Lysholm score at } 1-6 \text { months after treatment and WOMAC and SF- } 36 \\
\text { scale scores at } 2-6 \text { months after treatment were significantly improved, and no recurrence of } \\
\text { knee pain was observed. }\end{array}$ \\
\hline $\begin{array}{l}\text { Seven (knee OA with } \\
\text { full-thickness carti- } \\
\text { lage defects) [59] }\end{array}$ & $\begin{array}{l}7 \text { years of follow-up } \\
\text { after injection }\end{array}$ & Allogeneic UC-MSCs & $1.15-2 \times 10^{7}$ & HA & $\begin{array}{l}\text { The improved clinical outcomes were stable over } 7 \text { years of follow-up. There were no incidences of } \\
\text { osteogenesis or tumorigenesis over the } 7 \text { years of follow-up. }\end{array}$ \\
\hline $\begin{array}{l}17 \text { (unilateral ACL } \\
\text { reconstruction) [60] }\end{array}$ & $\begin{array}{l}26 \text { weeks of follow-up } \\
\text { after injection }\end{array}$ & Allogeneic MPCs & $7.5 \times 10^{7}$ & $\mathrm{HA}$ & $\begin{array}{l}\text { The MPC + HA group showed greater improvements in KOOS pain scores, symptoms, ADLs and SF- } \\
36 \text { bodily pain scores; reduced medial and lateral tibiofemoral joint space narrowing; less tibial } \\
\text { bone expansion; and a trend toward reduced tibial cartilage volume loss. }\end{array}$ \\
\hline 18 (knee OA) [61] & 96 weeks of follow-up & Autologous AD-MSCs & $1-5 \times 10^{7}$ & - & $\begin{array}{l}\text { IA injections of human AD-MSCs were safe and improved knee joint pain, function and cartilage } \\
\text { volume. The group treated with the dose of } 5 \times 10^{7} \mathrm{AD}-\mathrm{MSCs} \text { exhibited the greatest } \\
\text { improvement. }\end{array}$ \\
\hline 30 (knee OA) [62] & 4 years of follow-up & Autologous BM-MSCs & $1-10 \times 10^{7}$ & $\mathrm{HA}$ & $\begin{array}{l}\text { No adverse effects were reported after BM-MSCs administration or during follow-up. BM-MSC- } \\
\text { treated patients improved according to the median value (IQR) of the VAS score. }\end{array}$ \\
\hline 20 (knee OA) [63] & 24 weeks of follow-up & Allogeneic PL-MSCs & $5-6 \times 10^{8}$ & - & $\begin{array}{l}\text { Allogeneic PL-MSCs improved clinical measures of pain, symptoms, ADLs, QoL, S/R factors and knee } \\
\text { ROM, but improvements were sustained until only } 8 \text { weeks post-treatment. }\end{array}$ \\
\hline 30 (knee OA) [64] & 12 months of follow-up & Autologous AD-MSCs & $1 \times 10^{8}$ & - & $\begin{array}{l}\text { The AD-MSC-treated groups showed clinically significant improvements in pain and function at the } \\
\text { end of the 12-month follow-up period. Radiological analysis indicated modification of disease } \\
\text { progression. }\end{array}$ \\
\hline 40 (knee OA) [65] & $\begin{array}{l}52 \text { weeks of follow-up } \\
\text { after injection }\end{array}$ & UC-MSCs & $2 \times 10^{7}$ & $\mathrm{HA}$ & $\begin{array}{l}\text { Only MSC-treated patients experienced significant pain and functional improvements from base- } \\
\text { line }(P=0.001) \text {. In a phase } 1 / 2 \text { trial (NCTO2580695), repeated UC-MSC treatment was safe and } \\
\text { superior to active comparator in knee OA at } 1 \text {-year follow-up. }\end{array}$ \\
\hline
\end{tabular}




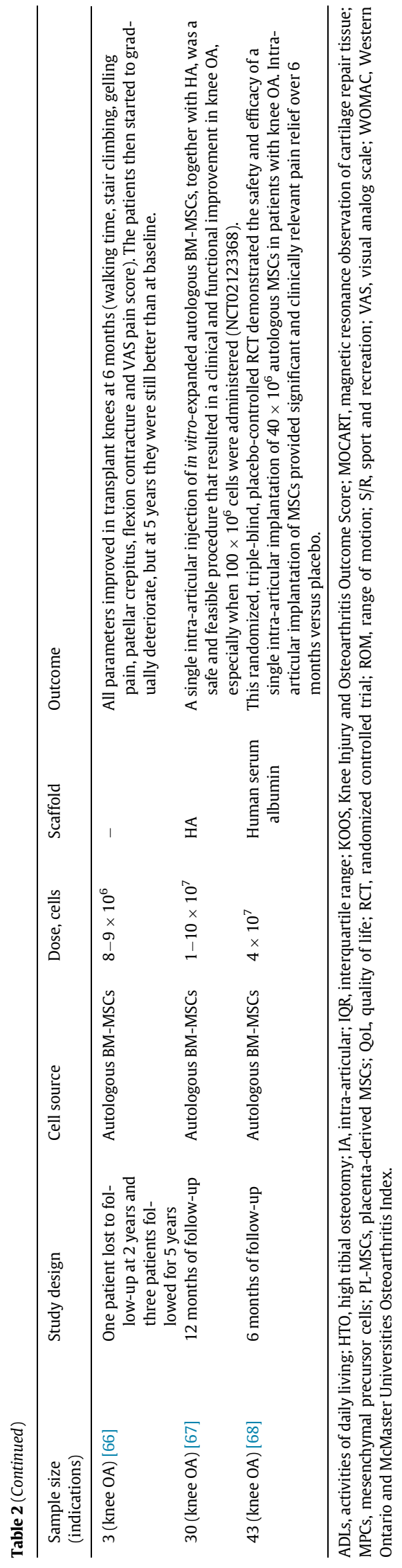

Abnormal activation of $\mathrm{OA}$ chondrocytes and the drift toward hypertrophy induce the secretion of abnormal types and quantities of matrix proteins and increase the expression and activity of matrixdegrading enzymes, which irreversibly changes the structural and functional integrity of articular cartilage [71,83]. During the development of $\mathrm{OA}$, articular chondrocytes express matrix proteins that do not belong to the normal cartilage matrix, such as type $\mathrm{X}$ collagen. MMP-13 and collagenase- 3 are the major cartilage-degrading collagenases [84]. Overexpression of these enzymes leads to characteristic changes in $\mathrm{OA}$ in mice, and results demonstrate that excessive MMP-13 activity can result in articular cartilage degradation and joint pathology of the kind observed in OA [85]. Similar to other proteases, MMP-13 is regulated at multiple levels, including transcription, activation and suppression. Chondrocytes can produce various tissue inhibitors of matrix metalloproteinases (TIMPs)-specific inhibitors of MMPs. TIMPs are present in articular cartilage and specifically balance and regulate the activity of matrix-degrading enzymes. In addition, TIMPs are considered good therapeutic targets for altering disease progression and structural damage [86,87]. In OA chondrocytes, MMP-13 gene expression can occur through mechanical stress and the actions of inflammatory cytokines and adipokines, which signal through different signaling cascades, including the MAPK cascade. These pathways affect a complex transcriptional network that includes transcription factors such as RUNX2, CEBP $\beta, E L F 3$, HIF- $2 \alpha$, CREB and ATF. Transactivation of MMP-13 in articular chondrocytes is also regulated by epigenetics [88].

In $\mathrm{OA}$, osteoblasts in subchondral bone respond to hypoxia in numerous ways. For example, osteoblasts upregulate $H I F-1 \alpha$. When osteoblasts are hypoxic (at oxygen partial pressures of $35-40 \mathrm{mmHg}$ ), the expression profile of their cytokines, proteins and growth factors (e.g., VEGF, insulin-like growth factor [IGF] II, transforming growth factor [TGF]- $\beta 1$, type I collagen and TIMP-1) changes. These changes, which are related to bone remodeling and increased cartilage degeneration, are hallmarks of histopathological OA [89]. In addition, OA osteoblasts express high levels of cytokines related to osteogenesis, especially osteocalcin, alkaline phosphatase and IGF-1, and are involved in inducing remodeling of the subchondral plate and subchondral trabecula. In one study, OA osteoblasts induced chondrocytes to acquire an OA-associated matrix mineralization and hypertrophy phenotype [90]. In turn, normal subchondral osteoblast formation was inhibited, and chondrocytes isolated from OA joints were co-cultured with osteoblasts to significantly activate ERK $1 / 2$ phosphorylation, suggesting that OA chondrocytes may avoid MAPK signaling pathwayinduced changes in the formation of subchondral bone osteoblasts [91]. However, whether subchondral bone thickening precedes the occurrence of cartilage fibrosis remains controversial.

\section{Synovial lesions in $O A$}

Usually, the joint synovium is only a few cell layers thick and is composed mainly of fibroblast-like synovial cells (FLSs). Proliferation of synovial cells and synovitis are among the main characteristics of OA. Histological analysis of the OA synovium shows that characteristic presentations in most OA patients are infiltration of immune cells such as dendritic cells (DCs), macrophages, natural killer (NK) cells and T cells [92]; synovial hyperplasia; MMP and ADAMTS production; and enhanced macrophage activity. Moreover, OA FLSs undergo phenotypic changes. Some researchers believe that the synovial reaction in $\mathrm{OA}$ is characterized by fibrosis accompanied by increased reactivity to TGF- $\beta$ [93]. Any damage to the meniscus or subchondral bone results in the release of ECM fragments, such as molecular fragments (e.g., fibronectin, collagen type II and cartilage oligomeric protein), with increased MMP and ADAMTS activity. At the same time, such fragments of molecules acts as a damage-associated molecular pattern to further activate FLSs via integrin or Toll-like receptor pathways [94]. Activated OA FLSs can secrete cytokines such as IL-1, 


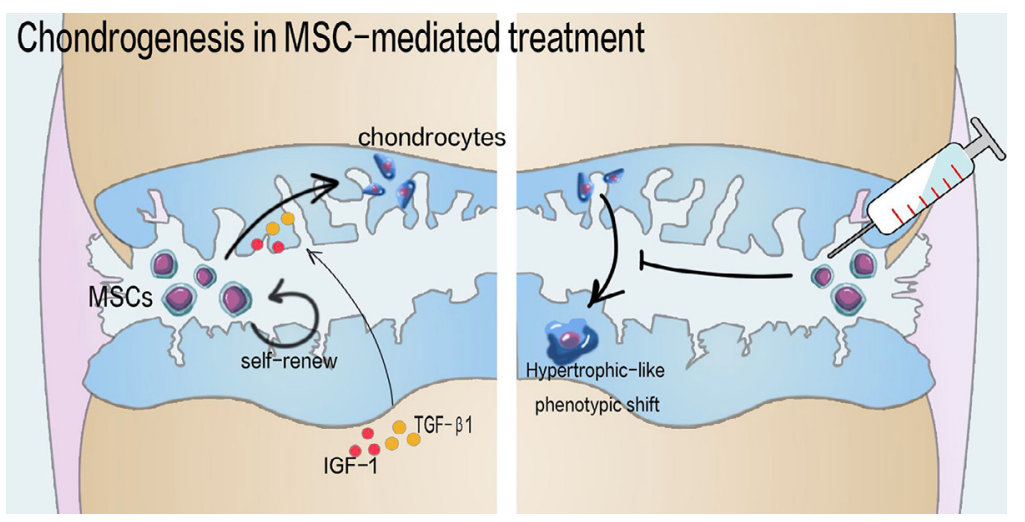

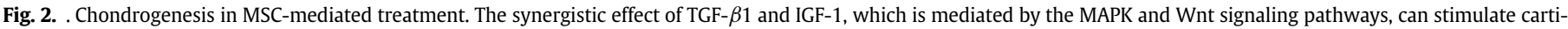

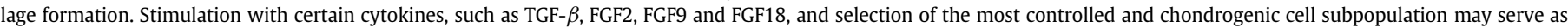
the approaches to address the limiting utility of MSCs in cartilage repair.

tumor necrosis factor alpha (TNF- $\alpha$ ) and IL-6 and can activate a variety of cellular signaling pathways, including the IL-6/STAT3 signaling pathway and Toll-like receptor surface receptor signaling, causing further cellular infiltration and angiogenesis while also providing catabolic signals to articular chondrocytes, thus stimulating articular chondrocytes [95] and damaging bone and cartilage [96,97].

In addition to these damage-related molecules, accumulating evidence indicates that factors directly related to the cartilage disease process affect the synovium, thereby promoting specific synovial reactions in FLSs. Indeed, Wnt $/ \beta$-catenin pathway inhibition was recently shown to reduce the severity of disease in a model of traumatic OA by inhibiting not only the degradation of chondrocytes but also fibrosis mediated by synovial fibroblasts [98]. These data not only solidify the concept of the synovial membrane but also reveal the mechanism by which FLSs are involved in the development of $\mathrm{OA}$. Moreover, these findings may facilitate the development of new treatment strategies for $\mathrm{OA}$.

\section{Chondrogenesis in MSC-mediated treatment}

MSCs can form cells of the mesoderm lineage and can differentiate into three lines of osteoblasts, chondrocytes and adipocytes. In in vitro experiments, multiple approaches to steer MSC differentiation in the direction of cartilage formation have been identified. The synergistic effect of TGF- $\beta 1$ and IGF-1, which is mediated by the MAPK and Wnt signaling pathways, can stimulate cartilage formation $[99,100]$. In vitro, MSC-derived chondrocytes can produce type II collagen and proteoglycan, similar to mature adult chondrocytes [100]. Other molecules found to steer MSC differentiation toward chondrocytes include dexamethasone [101] and some bone morphogenetic proteins, mainly bone morphogenetic protein 7 [102] and FGF2 [103].

Notch signaling is overactivated during OA progression, and intraarticular treatment with normal MSCs downregulates the Notch signaling pathway [104]. The transient receptor potential vanillin 4 ion channel, a calcium ion-permeable channel, has also been found to play an important role in the progression of mouse OA [105]. In addition, studies have shown that in animal models of OA, intra-articular injection of MSCs may inhibit the expression of MMP-13, TNF- $\alpha$ and IL-1 $\beta$ [106].

However, the reduction in cartilage cells and inadequate nutrient supply, coupled with the inefficiency of the true cartilage-type hyaluronic ECM produced by MSCs, result in the inability to perform functional healing responses, thereby limiting the utility of MSCs in cartilage repair [107]. In addition, mineralized nodules are produced in in vitro cultures of MSCs [108], and after ectopic implantation in mice, MSC clusters have been shown to gradually evolve from a phenotype of mineralization and angiogenesis to one of trabecular bone formation [109]. Stimulation with certain cytokines is one approach to addressing these key limitations. TGF- $\beta$-mediated inhibition of differentiation and hypertrophy in nascent cartilage is necessary for 7 weeks. However, alkaline phosphatase, type X collagen, parathyroid hormone 1 receptor, MMP13, VEGF and RUNX2 are simultaneously upregulated $[110,111]$. Alternatively, continuous exposure to FGF2, FGF9 and FGF18 enhances the tendency of MSCs to differentiate into cartilage and prevents further development into a terminal hypertrophic phenotype [112]. Another strategy is to select the most controlled and chondrogenic cell subpopulation. In a mouse model of collagen-induced arthritis, intra-articular injection of CD146+ MSCs more strongly inhibited Th17 cell activation and promoted cartilage protection compared with CD146- cells [113]. In addition, synovial membrane-derived MSCs rich in CD271, CD73 or CD105 have also proven to be a better choice for the treatment of focal chondropathy compared with other MSCs (Figure 2) [114-116].

\section{Immunoregulatory and paracrine effects of MSC treatment}

MSCs not only aid tissue regeneration but also exert beneficial effects through immunoregulatory and paracrine mechanisms and thus the control of disease processes. MSCs exert effective immunoregulatory and anti-inflammatory effects by regulating multiple cytokines, such as prostaglandin E2, interferon gamma and interleukins $[117,118]$. Prostaglandin E2 secreted by MSCs can promote the production of immunosuppressive IL-10 by binding to EP2 and EP4 receptors on macrophages and participate in the regulation of CD4+ effector T cells [119]. In addition, MSCs have been shown to inhibit Tcell proliferation and induce T-cell apoptosis, thereby stimulating phagocytic cells to produce TGF- $\beta$ and increasing the number of regulatory T cells [120]. MSCs also regulate innate immunity by inhibiting DC maturation and reducing NK cell cytotoxicity [121]. Moreover, MSCs can change the polarization of macrophages from the proinflammatory (M1) phenotype to the anti-inflammatory (M2) phenotype [122]. MSCs can interact with macrophages and inhibit their activation and the secretion of IL- $1 \beta$, TGF- $\alpha$ and other inflammatory factors [52].

In addition to exhibiting immunoregulatory and differentiation potential, MSCs express essential cytokines, including TGF- $\beta$, VEGF, epidermal growth factor and a range of mediators that stimulate local tissue repair. Bioactive molecules promote chondrocyte proliferation and ECM deposition and repair damaged bone and cartilage [123]. Moreover, the secretion of cytokines by mature chondrocytes can in turn promote the differentiation of MSCs into chondrocytes. Most recent studies have shown that MSCs participate in tissue repair by regulating local inflammation, apoptosis and cell proliferation through mainly paracrine mechanisms rather than via direct 


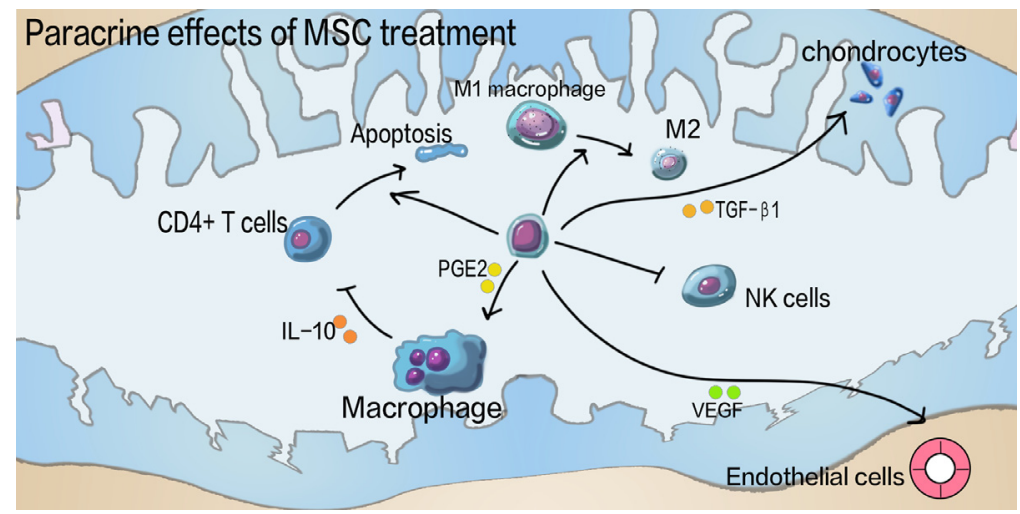

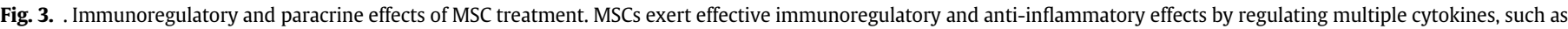

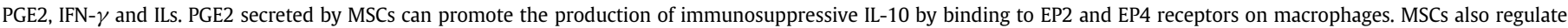

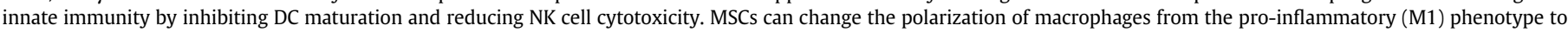

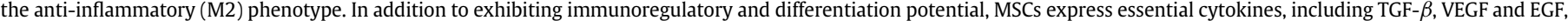
and a range of mediators that stimulate local tissue repair. EGF, epidermal growth factor; IFN- $\gamma$, interferon gamma; ILs, interleukins; PGE2, prostaglandin E2.

differentiation into chondrocytes. The potential paracrine effects of MSCs in OA treatment are summarized in Figure 3.

\section{Exosomes from MSCS}

Recently, the therapeutic potential of cytokine secretion by MSCs has been attributed to the release of exosomes. Exosomes are defined as nanoscale extracellular lipid bilayer vesicles derived from endocytosis. They transfer lipids, proteins and different kinds of RNAs, including regulatory circular RNAs and microRNAs (miRNAs), between cells. They fuse with the plasma membrane of target cells, are internalized by endocytosis or interact with cell surface receptors to activate intracellular signaling pathways. More and more studies have shown that the paracrine mechanism of MSC is through exosomes [124].

First, exosomes from MSCs (MSC-exos) can promote articular cartilage regeneration and improve ECM. Some researchers combined human iPSC-MSC-exos with photoinduced imine crosslinking hydrogels to form acellular tissue patches-EHG tissue patch (hiPSC-MSCsderived exosomes, HA-NB and Gelatin), that could fix exosomes and exert a positive role in cellular regulation and also implanted EHGs into the cartilage-deficient site in a rabbit model, finding after 12 weeks that the EHGs could accurately permeate and repair the cartilage defect [125]. Recent studies have found that BM-MSC-exo transplantation upregulates the SOX9 and Wnt7a genes related to chondrocyte regeneration and significantly downregulates the expression of genes related to hypertrophic chondrocyte differentiation, such as RUNX2, COL10A1 and ALP [126]. With regard to ECM, MSC-exos can promote glycosaminoglycan synthesis influenced by IL- $1 \beta$ and inhibit the production of nitric oxide and MMP-13 induced by IL- $1 \beta$ [31].

Second, MSC-exos have shown an immunosuppressive effect in many diseases. They can inhibit pro-inflammatory cytokines such as IL- $1 \beta$, IL- 6 and TNF- $\alpha$. In addition, exosomes may induce Th 1 cells to transform into Th2 cells and inhibit their ability to differentiate into Th17 cells [127]. Moreover, MSC-exos may play a beneficial role in the progression of OA through specific miRNAs. One study has shown that MSC-exos can reverse pathological inflammation through three specific miRNAs: miRNA21, miRNA-146a and miRNA-181c [128]. Exosome miRNA-125a can promote angiogenesis by targeting Dll4 [129]. MiRNA-100-5p inhibits mechanistic target of rapamycin autophagy as well as chondrocyte apoptosis by balancing anabolism and catabolism [130]. In the rat model, MSC exogenous miRNA-135b can promote cartilage repair by regulating TGF- $\beta$ [131].

However, the amount of miRNA in MSC-exos is relatively low and is affected by cell type, cell viability and cell environment. The exosomes of human embryonic stem cells are rich in pre-miRNA. By contrast, mature MSCs contain more mature miRNA than immature MSCs [132].

\section{Summary and Outlook}

\section{Problems that remain to be solved}

Despite the promise of MSCs for the treatment of OA, many issues have yet to be resolved. First, the mechanism of OA requires further clarification. Approaches to mimicking joint biomechanical changes have been used in numerous studies, suggesting that biomechanical forces play a key role in regulating cartilage growth and maintaining physiological cartilage homeostasis. Many other studies have shown that the inflammatory microenvironment at the time of OA development, including the synovial inflammation characterized by structural cartilage changes, is characterized by infiltration of immune cells, such as DCs, macrophages, NK cells and T cells. These effects may be the result of mild inflammation caused by metabolic syndrome, innate immunity or aging-related inflammation. This possibility requires further study.

Second, many questions remain about the biological behavior of MSCs. The precise microlocalization of MSCs in vivo remains a topic of debate. When tissue from a specific organ, such as bone marrow, is cultured, it can proliferate and differentiate into adherent cells with mature mesenchymal phenotypes, such as adipocytes, osteoblasts and chondrocytes. If these adherent cell populations meet the required standards, they can technically be called MSCs; however, whether these cells are representative of MSCs in vivo is undetermined. The properties of cells removed from the body are likely to change under culture conditions that do not mimic those found in their original niche [133]. With regard to inflammation, MSCs are thought to exhibit a dual behavior pattern in inflamed tissues; that is, they exhibit a unique ability to transform from a pre-inflammatory phenotype to an anti-inflammatory phenotype and interfere with innate and adaptive immune responses. Through this mechanism, MSCs promote homoeostasis between these opposing pathways [134].

Finally, the treatment of OA with MSCs focuses mainly on (i) cell sources (autologous/allogeneic), (ii) doses (tens to millions of MSCs), (iii) delivery systems (joint or surgical MSC stent transplantation/intraarticular MSC injection), (iv) number of injections and (v) combinations of MSCs with co-stimulatory factors (PRP, HA or growth factors). In addition, regarding the effectiveness and safety of MSC treatment, many qualitative and often subjective clinical measures are currently used to evaluate its efficacy, and data obtained from these measures may not truly represent the efficacy of treatment [135]. Although many 
researchers were initially concerned about MSC therapy, systematic reviews of clinical trials have shown that intravascular and intra-articular injections of MSCs are relatively safe; however, their long-term therapeutic efficacy and safety need further research. In addition, more reliable studies with larger sample sizes and randomized controls are needed to obtain more supportive evidence and to fully standardize and optimize the use of MSCs for the treatment of OA disease.

\section{Prospects}

In terms of cell preparation procedures, differentiation potential and long-lasting effects of MSCs, the best sources of MSCs are still speculative. Therefore, standardized cell sources and preparation methods are essential to assess the outcomes of regenerative therapy. Five MSC products have entered the market, but only two-Cartistem (producted by Medipost Co., Ltd. (Seongnam, South Korea)) and Stempeucel (producted by Stempeutics Research Pvt. Ltd (Bangalore, India))-have been approved as advanced therapy medicinal products for clinical application in the European Union.

Recently, the therapeutic potential of cytokine secretion by MSCs has been attributed to the release of EVs. EVs consist of small particles from the endolysosomal system and include exosomes (50-150 nm) and large vesicles $(100-500 \mathrm{~nm})$ that bud from the plasma membrane. EVs transfer lipids, proteins and different kinds of RNAs, including regulatory circular RNAs and miRNAs, between cells. Compared with similar cell-based drugs, the ultimate acellular therapy has multiple advantages, including lower product variability; higher repeatability; simpler storage; and better safety, dosage regimens and potency. In addition, this therapy can be tested by approaches similar to those used to test drugs [136].

MSC/biomaterial constructs for articular cartilage tissue engineering have also been designed. Among protein-based biomaterials, type I and type III collagens have been extensively tested because of their low immunogenicity and ability to mimic the proper structure of the natural cartilage microenvironment and support the adhesion, proliferation and differentiation status of MSCs. Fibrin is another proteinbased biomaterial widely used clinically because of its immunocompatibility. Although fibrin is characterized by low mechanical strength and rapid biodegradation, it can effectively support the proliferation of MSCs and their differentiation into cartilage [137]. In addition, silk fibroin is a biopolymer with superior biomechanical properties compared with those of synthetic polymers, with low immunogenicity after transplantation in vivo. Synthetic polymers, including PLA, PGA, PLA and PGA co-polymers, polylactide-coglycolide and poly- $\varepsilon$-caprolactone biomaterials such as lactone and polyethylene glycol, have good biocompatibility and biodegradability [138].

\section{Funding}

No funding was received.

\section{Declaration of Competing Interest}

The authors have no commercial, proprietary or financial interest in the products or companies described in this article.

\section{Author Contributions}

Conception and design of the study: WW. Acquisition of data: XZ, $\mathrm{JH}$ and WW. Analysis and interpretation of data: XZ, JH and WW. Drafting or revising the manuscript: XZ. All authors have approved the final article.

\section{References}

[1] Dequeker J, Luyten FP. The history of osteoarthritis-osteoarthrosis. Ann Rheum Dis 2008;67:5-10.

[2] Barnett R. Osteoarthritis. Lancet 2018;391:1985.

[3] Bijlsma JW, Berenbaum F, Lafeber FP. Osteoarthritis: an update with relevance for clinical practice. Lancet 2011;377:2115-26.

[4] Barbour KE, Helmick CG, Boring M, Brady TJ. Vital Signs: Prevalence of DoctorDiagnosed Arthritis and Arthritis-Attributable Activity Limitation-United States, 2013-2015. MMWR Morb Mortal Wkly Rep 2017;66:246-53.

[5] Disease GBD, Injury I, Prevalence C. Global, regional, and national incidence, prevalence, and years lived with disability for 354 diseases and injuries for 195 countries and territories, 1990-2017: a systematic analysis for the Global Burden of Disease Study 2017. Lancet 2018;392:1789-858.

[6] Huang Z, et al. Effectiveness of low-level laser therapy in patients with knee osteoarthritis: a systematic review and meta-analysis. Osteoarthritis Cartilage $2015 ; 23: 1437-44$.

[7] Blagojevic M, Jinks C, Jeffery A, Jordan KP. Risk factors for onset of osteoarthritis of the knee in older adults: a systematic review and meta-analysis. Osteoarthritis Cartilage 2010;18:24-33.

[8] Aspden RM, Saunders FR. Osteoarthritis as an organ disease: from the cradle to the grave. European cells \& materials 2019;37:74-87.

[9] Aspden RM. Obesity punches above its weight in osteoarthritis. Nature reviews. Rheumatology 2011;7:65-8.

[10] Hawker G, et al. A clinical decision rule to enhance targeted bone mineral density testing in healthy mid-life women. Osteoporosis international: a journa established as result of cooperation between the European Foundation for Osteoporosis and the National Osteoporosis Foundation of the USA 2012;23:1931-8.

[11] Nelson AE, Allen KD, Golightly YM, Goode AP, Jordan JM. A systematic review of recommendations and guidelines for the management of osteoarthritis: the chronic osteoarthritis management initiative of the U.S. bone and joint initiative. Seminars in arthritis and rheumatism 2014;43:701-12.

[12] Coxib, et al. Vascular and upper gastrointestinal effects of non-steroidal antiinflammatory drugs: meta-analyses of individual participant data from randomised trials. Lancet 2013;382:769-79.

[13] Stevens RM, et al. Randomized, Double-Blind, Placebo-Controlled Trial of Intraarticular Trans-Capsaicin for Pain Associated With Osteoarthritis of the Knee. Arthritis \& rheumatology (Hoboken, N.J.) 2019;71:1524-33

[14] Fleischmann RM, et al. A Phase II Trial of Lutikizumab, an Anti-Interleukin-1alpha beta Dual Variable Domain Immunoglobulin. Knee Osteoarthritis Patients With Synovitis. Arthritis \& rheumatology (Hoboken, N.J.) 2019;71:1056-69.

[15] Wang W, Cao W. Treatment of osteoarthritis with mesenchymal stem cells. Sci China Life Sci 2014;57:586-95.

[16] Muchedzi TA, Roberts SB. A systematic review of the effects of platelet rich plasma on outcomes for patients with knee osteoarthritis and following total knee arthroplasty. The surgeon: journal of the Royal Colleges of Surgeons of Edinburgh and Ireland 2018:16:250-8.

[17] Evans JT, et al. How long does a knee replacement last? A systematic review and meta-analysis of case series and national registry reports with more than 15 years of follow-up. Lancet 2019;393:655-63.

[18] Wilson HA, et al. Patient relevant outcomes of unicompartmental versus tota knee replacement: systematic review and meta-analysis. BMJ (Clinical research ed.) 2019;364:1352.

[19] Cahill KE, Leukam MJ, Riedell PA. Refining patient selection for CAR T-cell therapy in aggressive large B-cell lymphoma. Leuk Lymphoma 2020;61:799-807.

[20] Morizane A. [Cell therapy for Parkinson's disease with induced pluripotent stem cells]. Rinsho Shinkeigaku 2019;59:119-24.

[21] Vanikar AV, Trivedi HL, Thakkar UG. Stem cell therapy emerging as the key player in treating type 1 diabetes mellitus. Cytotherapy 2016;18:1077-86

[22] Ebert AD, et al. Induced pluripotent stem cells from a spinal muscular atrophy patient. Nature 2009;457:277-80.

[23] Kohn DB. Historical Perspective on the Current Renaissance for Hematopoietic Stem Cell Gene Therapy. Hematology/oncology clinics of North America 2017:31:721-35

[24] Murphy C, Mobasheri A, Tancos Z, Kobolak J, Dinnyes A. The Potency of Induced Pluripotent Stem Cells in Cartilage Regeneration and Osteoarthritis Treatment Advances in experimental medicine and biology 2018;1079:55-68.

[25] Vangsness Jr CT, et al. Adult human mesenchymal stem cells delivered via intraarticular injection to the knee following partial medial meniscectomy: a randomized, double-blind, controlled study. The Journal of bone and joint surgery. American volume 2014:96:90-8.

[26] Murphy JM, Fink DJ, Hunziker EB, Barry FP. Stem cell therapy in a caprine model of osteoarthritis. Arthritis Rheum 2003;48:3464-74

[27] Lee KB, Hui JH, Song IC, Ardany L, Lee EH, et al. Injectable mesenchymal stem cel therapy for large cartilage defects-a porcine model. Stem Cells 2007;25:2964_ 71.

[28] Koga H, et al. Local adherent technique for transplanting mesenchymal stem cells as a potential treatment of cartilage defect. Arthritis research \& therapy 2008; $10:$ R84

[29] Guo X, et al. Repair of osteochondral defects with biodegradable hydrogel composites encapsulating marrow mesenchymal stem cells in a rabbit model. Acta biomaterialia 2010;6:39-47.

[30] Sato M, et al. Direct transplantation of mesenchymal stem cells into the knee joints of Hartley strain guinea pigs with spontaneous osteoarthritis. Arthritis research \& therapy 2012;14:R31. 
[31] Kuroda K, et al. The paracrine effect of adipose-derived stem cells inhibits osteoarthritis progression. BMC musculoskeletal disorders 2015;16:236.

[32] Saulnier N, et al. Intra-articular administration of xenogeneic neonatal mesenchymal stromal cells early after meniscal injury down-regulates metalloproteinase gene expression in synovium and prevents cartilage degradation in a rabbit model of osteoarthritis. Osteoarthritis Cartilage 2015;23:122-33.

[33] Yun S, Ku SK, Kwon YS. Adipose-derived mesenchymal stem cells and plateletrich plasma synergistically ameliorate the surgical-induced osteoarthritis in Beagle dogs. Journal of orthopaedic surgery and research 2016;11:9.

[34] Joswig AJ, et al. Repeated intra-articular injection of allogeneic mesenchymal stem cells causes an adverse response compared to autologous cells in the equine model. Stem cell research \& therapy 2017;8:42.

[35] Zhang BY, et al. Evaluation of the Curative Effect of Umbilical Cord Mesenchymal Stem Cell Therapy for Knee Arthritis in Dogs Using Imaging Technology. Stem cells international 2018;2018:1983025

[36] Magri C, et al. Comparison of efficacy and safety of single versus repeated intraarticular injection of allogeneic neonatal mesenchymal stem cells for treatment of osteoarthritis of the metacarpophalangeal/metatarsophalangeal joint in horses: a clinical pilot study. PLoS One 2019;14:9. e0221317.

[37] Mahmoud EE, Adachi N, Mawas AS, Deie M, Ochi M. Multiple intra-articular injections of allogeneic bone marrow-derived stem cells potentially improve knee lesions resulting from surgically induced osteoarthritis: an animal study The bone \& joint journal 2019;101-b:824-31.

[38] Wu KC, Chang YH, Liu HW, Ding DC. Transplanting human umbilical cord mes enchymal stem cells and hyaluronate hydrogel repairs cartilage of osteoarthritis in the minipig model. Ci ji yi xue za zhi = Tzu-chi medical journal 2019;31:11-9.

[39] Desando G et al. Autologous Bone Marrow Concentrate in a Sheep Model of Osteoarthritis: New Perspectives for Cartilage and Meniscus Repair. Tissue engineering. Part C, Methods 2016;22:608-19.

[40] Tseng WJ, et al. Treatment of osteoarthritis with collagen-based scaffold: a porcine animal model with xenograft mesenchymal stem cells. Histology and histopathology 2018;33:1271-86.

[41] Muir P, et al. Autologous Bone Marrow-Derived Mesenchymal Stem Cells Modulate Molecular Markers of Inflammation in Dogs with Cruciate Ligament Rupture. PLoS One 2016;11:e0159095.

[42] Jeon HJ, et al. Therapeutic Effects of Human Umbilical Cord Blood-Derived Mesenchymal Stem Cells Combined with Cartilage Acellular Matrix Mediated Via Bone Morphogenic Protein 6 in a Rabbit Model of Articular Cruciate Ligament Transection. Histology and histopathology 2020;16:596-611.

[43] Huňáková K, et al. Study of bilateral elbow joint osteoarthritis treatment using conditioned medium from allogeneic adipose tissue-derived MSCs in Labrador retrievers. Research in veterinary science 2020;132:513-20 e0159095

[44] He A, et al. Repair of osteochondral defects with in vitro engineered cartilage based on autologous bone marrow stromal cells in a swine model. Sci Rep 2017;7:40489.

[45] Zhang ZZ, et al. 3D-Printed Poly( $\varepsilon$-caprolactone) Scaffold Augmented With Mesenchymal Stem Cells for Total Meniscal Substitution: A 12- and 24-Week Animal Study in a Rabbit Model. The American journal of sports medicine 2017; 45:1497-511.

[46] Kremen Jr. TJ, et al. A Translational Porcine Model for Human Cell-Based Therapies in the Treatment of Posttraumatic Osteoarthritis After Anterior Cruciate Ligament Injury. The American journal of sports medicine 2020;48:1497-511.

[47] Wei JP, et al. Human amniotic mesenchymal cells differentiate into chondrocytes. Cloning and stem cells 2009;11:19-26.

[48] Shen W, et al. Intra-articular injection of human meniscus stem/progenitor cells promotes meniscus regeneration and ameliorates osteoarthritis through stroma cell-derived factor-1/CXCR4-mediated homing. Stem cells translational medicine 2014;3:387-94.

[49] Zhang S, et al. Exosomes derived from human embryonic mesenchymal stem cells promote osteochondral regeneration. Osteoarthritis Cartilage 2016;24:2135-40.

[50] Varma HS, Dadarya B, Vidyarthi A. The new avenues in the management of osteo-arthritis of knee-stem cells. Journal of the Indian Medical Association 2010;108:583-5

[51] Koh YG, Choi YJ. Infrapatellar fat pad-derived mesenchymal stem cell therapy for knee osteoarthritis. The Knee 2012;19:902-7.

[52] Jo $\mathrm{CH}$, et al. Intra-articular injection of mesenchymal stem cells for the treatment of osteoarthritis of the knee: a proof-of-concept clinical trial. Stem Cells 2014;32:1254-66.

[53] Centeno CJ, et al. Regeneration of meniscus cartilage in a knee treated with percutaneously implanted autologous mesenchymal stem cells. Medical hypotheses 2019;21:54-63.

[54] Davatchi F, Abdollahi BS, Mohyeddin M, Shahram F, Nikbin B. Mesenchymal stem cell therapy for knee osteoarthritis. Preliminary report of four patients. International journal of rheumatic diseases 2011;14:211-5.

[55] Wong KL, et al. Injectable cultured bone marrow-derived mesenchymal stem cells in varus knees with cartilage defects undergoing high tibial osteotomy: a prospective, randomized controlled clinical trial with 2 years' follow-up. Arthroscopy: the journal of arthroscopic \& related surgery: official publication of the Arthroscopy Association of North America and the International Arthroscopy Association 2013;29:2020-8.

[56] Orozco L, et al. Treatment of knee osteoarthritis with autologous mesenchyma stem cells: a pilot study. Transplantation 2013;95:1535-41.

[57] Pers YM, et al. Adipose Mesenchymal Stromal Cell-Based Therapy for Severe Osteoarthritis of the Knee: A Phase I Dose-Escalation Trial. Stem cells translational medicine 2016;5:847-56

[58] Wang Y, et al. Curative effect of human umbilical cord mesenchymal stem cells by intra-articular injection for degenerative knee osteoarthritis. Arthroscopy: the journal of arthroscopic \& related surgery: official publication of the Arthroscopy Association of North America and the International Arthroscopy Association 2016:30:1472-7.

[59] Park YB, Ha CW, Lee CH, Yoon YC, Park YG. Cartilage Regeneration in Osteoarthritic Patients by a Composite of Allogeneic Umbilical Cord Blood-Derived Mesenchymal Stem Cells and Hyaluronate Hydrogel: Results from a Clinical Trial for Safety and Proof-of-Concept with 7 Years of Extended Follow-Up. Stem cells translational medicine 2017;6:613-21

[60] Wang Y, et al. Safety, tolerability, clinical, and joint structural outcomes of a single intra-articular injection of allogeneic mesenchymal precursor cells in patients following anterior cruciate ligament reconstruction: a controlled double-blind randomised trial. Stem cells translational medicine 2017:19:180.

[61] Song Y, et al. Human adipose-derived mesenchymal stem cells for osteoarthritis: a pilot study with long-term follow-up and repeated injections. Regenerative medicine 2018;13:297-307.

[62] Lamo-Espinosa JM, et al. Intra-articular injection of two different doses of autologous bone marrow mesenchymal stem cells versus hyaluronic acid in the treatment of knee osteoarthritis: long-term follow up of a multicenter randomized controlled clinical trial (phase I/II). Regenerative medicine 2018;16:213.

[63] Khalifeh Soltani S, et al. Safety and efficacy of allogenic placental mesenchymal stem cells for treating knee osteoarthritis: a pilot study. Cytotherapy 2019;21:54-63.

[64] Freitag J, et al. Adipose-derived mesenchymal stem cell therapy in the treatment of knee osteoarthritis: a randomized controlled trial. Regenerative medicine 2019; 14:213-30.

[65] Matas J, et al. Umbilical Cord-Derived Mesenchymal Stromal Cells (MSCs) for Knee Osteoarthritis: Repeated MSC Dosing Is Superior to a Single MSC Dose and to Hyaluronic Acid in a Controlled Randomized Phase I/II Trial. Stem cells translational medicine 2019;8:215-24.

[66] Davatchi F, Sadeghi Abdollahi B, Mohyeddin M, Nikbin B. Mesenchymal stem cell therapy for knee osteoarthritis: 5 years follow-up of three patients. International journal of rheumatic diseases 2016;19:219-25.

67] Lamo-Espinosa JM, et al. Intra-articular injection of two different doses of autologous bone marrow mesenchymal stem cells versus hyaluronic acid in the treatment of knee osteoarthritis: multicenter randomized controlled clinical trial (phase I/II). Journal of translational medicine 2016;14:246.

[68] Delgado-Enciso I, et al. A phase I-II controlled randomized trial using a promising novel cell-free formulation for articular cartilage regeneration as treatment of severe osteoarthritis of the knee. European journal of medical research 2018;23:52.

[69] Qureshi AH, et al. Proteomic and phospho-proteomic profile of human platelets in basal, resting state: insights into integrin signaling. PLoS One 2009;4:e7627.

[70] Maniwa S, et al. Effects of hyaluronic acid and basic fibroblast growth factor on motility of chondrocytes and synovial cells in culture. Acta orthopaedica Scandinavica 2001;72:299-303

[71] Goldring SR, Goldring MB. Changes in the osteochondral unit during osteoarthritis: structure, function and cartilage-bone crosstalk. Nature reviews. Rheumatology 2016;12:632-44.

[72] Zhong L, Huang X, Karperien M, Post JN. Correlation between Gene Expression and Osteoarthritis Progression in Human. International journal of molecular sciences 2016;17:1126.

[73] Zhang Q et al. SOX9 is a regulator of ADAMTSs-induced cartilage degeneration at the early stage of human osteoarthritis. Osteoarthritis Cartilage 2015;23:2259-68.

[74] Otero M, et al. ELF3 modulates type II collagen gene (COL2A1) transcription in chondrocytes by inhibiting SOX9-CBP/p300-driven histone acetyltransferase activity. Connective tissue research 2017;58:15-26.

[75] Wondimu EB, et al. Elf3 Contributes to Cartilage Degradation in vivo in a Surgical Model of Post-Traumatic Osteoarthritis. Sci Rep 2018;8:6438.

[76] Yan H, et al. Suppression of NF-kappaB activity via nanoparticle-based siRNA delivery alters early cartilage responses to injury. Proc Natl Acad Sci U S A 2016;113. E6199-E6208.

[77] Olivotto E, et al. IKKalpha/CHUK regulates extracellular matrix remodeling independent of its kinase activity to facilitate articular chondrocyte differentiation. PLoS One 2013;8:e73024

[78] Matsuzaki T, et al. Disruption of Sirt1 in chondrocytes causes accelerated progression of osteoarthritis under mechanical stress and during ageing in mice. Ann Rheum Dis 2014;73:1397-404.

[79] Monteagudo S, et al. DOT1L safeguards cartilage homeostasis and protects against osteoarthritis. Nature communications 2017:8:15889.

[80] Bachman M, et al. 5-Hydroxymethylcytosine is a predominantly stable DNA modification. Nature chemistry 2014;6:1049-55.

[81] Haseeb A, Makki MS, Haqqi TM. Modulation of ten-eleven translocation 1 (TET1), Isocitrate Dehydrogenase (IDH) expression, alpha-Ketoglutarate (alpha$\mathrm{KG}$ ), and DNA hydroxymethylation levels by interleukin-1beta in primary human chondrocytes. J Biol Chem 2014;289:6877-85

[82] Alvarez-Garcia O, et al. Increased DNA Methylation and Reduced Expression of Transcription Factors in Human Osteoarthritis Cartilage. Arthritis \& rheumatology (Hoboken, N.J.) 2016;68:1876-86.

[83] Sun MM, Beier F. Chondrocyte hypertrophy in skeletal development, growth, and disease. Birth defects research. Part C, Embryo today: reviews 2014;102:7482 .

[84] Billinghurst RC, et al. Enhanced cleavage of type II collagen by collagenases in osteoarthritic articular cartilage. J Clin Invest 1997:99:1534-45. 
[85] Neuhold LA, et al. Postnatal expression in hyaline cartilage of constitutively active human collagenase-3 (MMP-13) induces osteoarthritis in mice. J Clin Invest 2001:107:35-44.

[86] Yamamoto K, Murphy G, Troeberg L. Extracellular regulation of metalloproteinases. Matrix biology: journal of the International Society for Matrix Biology 2015;44-46:255-63.

[87] Yamamoto K, et al. Inhibition of Shedding of Low-Density Lipoprotein ReceptorRelated Protein 1 Reverses Cartilage Matrix Degradation in Osteoarthritis. Arthritis \& rheumatology (Hoboken, N.J.) 2017;69:1246-56.

[88] Singh P, Marcu KB, Goldring MB, Otero M. Phenotypic instability of chondrocytes in osteoarthritis: on a path to hypertrophy. Annals of the New York Academy of Sciences 2019;1442:17-34.

[89] Warren SM, et al. Hypoxia regulates osteoblast gene expression. The Journal of surgical research 2001;99:147-55.

[90] Sanchez C, et al. Subchondral bone osteoblasts induce phenotypic changes in human osteoarthritic chondrocytes. Osteoarthritis Cartilage 2005;13:988-97.

[91] Prasadam I, et al. Osteoarthritic cartilage chondrocytes alter subchondral bone osteoblast differentiation via MAPK signalling pathway involving ERK1/2. Bone 2010;46:226-35.

[92] Sokolove J, Lepus CM. Role of inflammation in the pathogenesis of osteoarthritis: latest findings and interpretations. Therapeutic advances in musculoskeletal disease 2013;5:77-94.

[93] Remst DF, et al. Gene expression analysis of murine and human osteoarthritis synovium reveals elevation of transforming growth factor beta-responsive genes in osteoarthritis-related fibrosis. Arthritis \& rheumatology (Hoboken, N.J.) 2014;66:647-56

[94] Pap T, Dankbar B, Wehmeyer C, Korb-Pap A, Sherwood J. Synovial fibroblasts and articular tissue remodelling: role and mechanisms. Seminars in cell \& developmental biology 2020;101:140-5.

[95] Loeser RF. The effects of aging on the development of osteoarthritis. HSS journal: the musculoskeletal journal of Hospital for Special Surgery 2012;8:18-9.

[96] Sun S, et al. The active form of MMP-3 is a marker of synovial inflammation and cartilage turnover in inflammatory joint diseases. BMC musculoskeletal disorders 2014;15:93.

[97] Li X, et al. GACAT3 promoted proliferation of osteoarthritis synoviocytes by IL-6/ STAT3 signaling pathway. European review for medical and pharmacological sciences 2018;22:5114-20.

[98] Lietman C, et al. Inhibition of Wnt/beta-catenin signaling ameliorates osteoarthritis in a murine model of experimental osteoarthritis. JCI insight 2018;3:e96308.

[99] Zhou S, Eid K, Glowacki J. Cooperation between TGF-beta and Wnt pathways during chondrocyte and adipocyte differentiation of human marrow stromal cells. Journal of bone and mineral research: the official journal of the American Society for Bone and Mineral Research 2004;19:463-70.

[100] Longobardi L, et al. Effect of IGF-I in the chondrogenesis of bone marrow mesenchymal stem cells in the presence or absence of TGF-beta signaling. Journal of bone and mineral research: the official journal of the American Society for Bone and Mineral Research 2006;21:626-36.

[101] Bosnakovski D, et al. Isolation and multilineage differentiation of bovine bone marrow mesenchymal stem cells. Cell Tissue Res 2005;319:243-53.

[102] Knippenberg M, Helder MN, Zandieh Doulabi B, Wuisman PI, Klein-Nulend J. Osteogenesis versus chondrogenesis by BMP-2 and BMP-7 in adipose stem cells. Biochem Biophys Res Commun 2006;342:902-8.

[103] Solchaga LA, et al. Repair of osteochondral defects with hyaluronan- and polyester-based scaffolds. Osteoarthritis Cartilage 2005;13:297-309.

[104] Horie M, et al. Intra-articular injection of human mesenchymal stem cells (MSCs) promote rat meniscal regeneration by being activated to express Indian hedgehog that enhances expression of type II collagen. Osteoarthritis Cartilage 2012;20:1197-207.

[105] Clark AL, Votta BJ, Kumar S, Liedtke W, Guilak F. Chondroprotective role of the osmotically sensitive ion channel transient receptor potential vanilloid 4: ageand sex-dependent progression of osteoarthritis in Trpv4-deficient mice. Arthritis Rheum 2010;62:2973-83.

[106] Desando G, et al. Intra-articular delivery of adipose derived stromal cells attenuates osteoarthritis progression in an experimental rabbit model. Arthritis research \& therapy 2013;15:R22.

[107] Somoza RA, Welter JF, Correa D, Caplan AI. Chondrogenic differentiation of mesenchymal stem cells: challenges and unfulfilled expectations. Tissue engineering. Part B, Reviews 2014;20:596-608.

[108] Abrahamsson CK, et al. Chondrogenesis and mineralization during in vitro culture of human mesenchymal stem cells on three-dimensional woven scaffolds. Tissue Eng Part A 2010;16:3709-18.

[109] Pelttari K, et al. Premature induction of hypertrophy during in vitro chondrogenesis of human mesenchymal stem cells correlates with calcification and vascular invasion after ectopic transplantation in SCID mice. Arthritis Rheum 2006;54:3254-66.
[110] Giuliani N, et al. New insights into osteogenic and chondrogenic differentiation of human bone marrow mesenchymal stem cells and their potential clinical applications for bone regeneration in pediatric orthopaedics. Stem cells international 2013;2013:312501.

[111] Mueller MB, Tuan RS. Functional characterization of hypertrophy in chondrogenesis of human mesenchymal stem cells. Arthritis Rheum 2008;58:1377-88.

[112] Correa D, et al. Sequential exposure to fibroblast growth factors (FGF) 2, 9 and 18 enhances hMSC chondrogenic differentiation. Osteoarthritis Cartilage 2015;23:443-53.

[113] Wu CC, Liu FL, Sytwu HK, Tsai CY, Chang DM. CD146+ mesenchymal stem cells display greater therapeutic potential than CD146- cells for treating collageninduced arthritis in mice. Stem cell research \& therapy 2016;7:23.

[114] Gullo F, De Bari C. Prospective purification of a subpopulation of human synovial mesenchymal stem cells with enhanced chondro-osteogenic potency. Rheumatology (Oxford, England) 2013;52:1758-68.

[115] Hermida-Gomez T, et al. Bone marrow cells immunomagnetically selected for CD271+ antigen promote in vitro the repair of articular cartilage defects. Tissue Eng Part A 2011;17:1169-79.

[116] Arufe MC, De la Fuente A, Fuentes-Boquete I, De Toro FJ, Blanco FJ. Differentiation of synovial CD-105(+) human mesenchymal stem cells into chondrocytelike cells through spheroid formation. J Cell Biochem 2009;108:145-55.

[117] Gray A, et al. The effect of local anesthetic on pro-inflammatory macrophage modulation by mesenchymal stromal cells. Int Immunopharmacol 2016;33:48-54.

[118] Yi T, Song SU. Immunomodulatory properties of mesenchymal stem cells and their therapeutic applications. Archives of pharmacal research 2012;35:213-21.

[119] Duffy MM, et al. Mesenchymal stem cell inhibition of T-helper 17 cell- differentiation is triggered by cell-cell contact and mediated by prostaglandin E2 via the EP4 receptor. European journal of immunology 2011;41:2840-51.

[120] Pers YM, Ruiz M, Noel D, Jorgensen C. Mesenchymal stem cells for the management of inflammation in osteoarthritis: state of the art and perspectives. Osteoarthritis Cartilage 2015;23:2027-35.

[121] Wang S, et al. Mesenchymal stem cells and immune disorders: from basic science to clinical transition. Frontiers of medicine 2019;13:138-51.

[122] Kim J, Hematti P. Mesenchymal stem cell-educated macrophages: a novel type of alternatively activated macrophages. Experimental hematology 2009;37:1445-53.

[123] Mamidi MK, Das AK, Zakaria Z, Bhonde R. Mesenchymal stromal cells for cartilage repair in osteoarthritis. Osteoarthritis Cartilage 2016;24:1307-16.

[124] Witwer KW, et al. Defining mesenchymal stromal cell (MSC)-derived small extracellular vesicles for therapeutic applications. Journal of extracellular vesicles 2019;8:1609206.

[125] Liu X, et al. Integration of stem cell-derived exosomes with in situ hydrogel glue as a promising tissue patch for articular cartilage regeneration. Nanoscale 2017;9:4430-8.

[126] Vonk LA, et al. Mesenchymal Stromal/stem Cell-derived Extracellular Vesicles Promote Human Cartilage Regeneration In Vitro. Theranostics 2018;8:906-20.

[127] Chen W, et al. Immunomodulatory effects of mesenchymal stromal cells-derived exosome. Immunologic research 2016;64:831-40.

[128] Ti D, Hao H, Fu X, Han W. Mesenchymal stem cells-derived exosomal microRNAs contribute to wound inflammation. Sci China Life Sci 2016:59:1305-12.

[129] Liang X, Zhang L, Wang S, Han Q, Zhao RC. Exosomes secreted by mesenchymal stem cells promote endothelial cell angiogenesis by transferring miR-125a. Journal of cell science 2016;129:2182-9.

[130] Wu J, et al. miR-100-5p-abundant exosomes derived from infrapatellar fat pad MSCs protect articular cartilage and ameliorate gait abnormalities via inhibition of mTOR in osteoarthritis. Biomaterials 2019;206:87-100.

[131] Wang R, Xu B, Xu H. TGF- $\beta 1$ promoted chondrocyte proliferation by regulating Sp1 through MSC-exosomes derived miR-135b. Cell Cycle 2018;17:2756-65.

[132] Baglio SR, et al. Human bone marrow- and adipose-mesenchymal stem cells secrete exosomes enriched in distinctive miRNA and tRNA species. Stem cell research \& therapy 2015;6:127.

[133] da Silva Meirelles L, Bellagamba BC, Camassola M, Nardi NB. Mesenchymal stem cells and their relationship to pericytes. Frontiers in bioscience (Landmark edition) 2016:21:130-56.

[134] Bernardo ME, Fibbe WE. Mesenchymal stromal cells: sensors and switchers of inflammation. Cell Stem Cell 2013;13:392-402.

[135] Shariatzadeh M, Song J, Wilson SL. The efficacy of different sources of mesenchymal stem cells for the treatment of knee osteoarthritis. Cell Tissue Res 2019;378:399-410.

[136] Crivelli B, et al. Mesenchymal stem/stromal cell extracellular vesicles: from active principle to next generation drug delivery system. Journal of controlled release: official journal of the Controlled Release Society 2017;262:104-17.

[137] Bensaid W, et al. A biodegradable fibrin scaffold for mesenchymal stem cell transplantation. Biomaterials 2003:24:2497-502.

[138] Colombini A, et al. Mesenchymal stem cells in the treatment of articular cartilage degeneration: new biological insights for an old-timer cell. Cytotherapy 2019;21:1179-97. 